\title{
Complicated hydatid cysts of the liver: A report of two cases
}

\author{
Abdelilah Mouhsine ${ }^{1,}$, Ahmed Belkouch ${ }^{2}$, El Mehdi Atmane ${ }^{1}$, Redouane Rokhssi ${ }^{1}$, \\ Youssef Berrada ${ }^{1}$, Lahcen Belyamani ${ }^{2}$, Abdelghani El Fikri ${ }^{1}$, M'barek Mahfoudi ${ }^{1}$ \\ ${ }^{1}$ Service de Radiologie Hôpital Militaire Avicenne, faculty of medecine and pharmacy, Marrakech, Maroc \\ ${ }^{2}$ Service des urgences Hôpital Militaire d'Instruction MohamedV, faculty of medecine and pharmacy, Rabat, Maroc
}

\section{Email address:}

abdelilahmouhsine@yahoo.fr(A. Mouhsine),belkouch1@gmail.com (A. Belkouch)

\section{To cite this article:}

Abdelilah Mouhsine, Ahmed Belkouch, El Mehdi Atmane, Redouane Rokhssi, Youssef Berrada, Lahcen Belyamani, Abdelghani El Fikri, M'barek Mahfoudi. Complicated Hydatid Cysts of the Liver: A Report of Two Cases. International Journal of Medical Imaging.

Vol. 2, No. 5, 2014, pp. 105-108. doi: 10.11648/j.jimi.20140205.12

\begin{abstract}
The authors report two cases of complicated hydatid cysts of the liver, including one which was spontaneously broken in the bile ducts and the other fistulized in the right pleura. Patients presented with jaundice and biliary colic in the first case. Cough basithoracic pain, weakness, and fever in the second. Both patients were investigated by ultrasound and CT scan followed by a hydatid serology. In both cases the patients improved after surgical treatment. Will be recalled imaging aspects of these two complications.
\end{abstract}

Keywords: Liver Hydatid Cyst, Clinical Presentation, Complications, Imaging

\section{Introduction}

Hydatid cyst of the liver remains a common disease in the Maghreb countries. Despite the availability of imaging (ultrasound, CT and MRI), it is still discovered at the stage of complication. The most common and most serious of these complications remains the cysto-biliary fistula.

Surgical treatment continues to be improved and should be as conservative as possible to reduce the morbidity and mortality of this benign condition.

\section{Case Presentation}

\subsection{Case 1}

A 34 years old man, farmer, with notion of contact with dogs, complained of hepatalgia since eight months.

One month before his admission to the hospital, the patient presented a generalized pruritus and a muco-cutaneous jaundice, without fever.

An abdominal ultrasound showed a cystic formation of segment VII measuring $6 \mathrm{~cm}$, a calcified formation of segment IV and a marked dilatation of the intrahepatic bile ducts and the common bile duct. A CT scan, performed before and after injection of contrast material (different arterial and portal venous phase), objectified two cystic formations; one was located in segment IV containing peripheral calcifications, measuring $6 / 4.5 \mathrm{~cm}$ and fistulized in intrahepatic bile ducts which were dilated (Figure 1, 2a and b). The other lesion was located in segment VII, had a fluid density with membrane peeling in some parts of it, containing some peripheral calcifications and measuring $6 / 4 \mathrm{~cm}$.
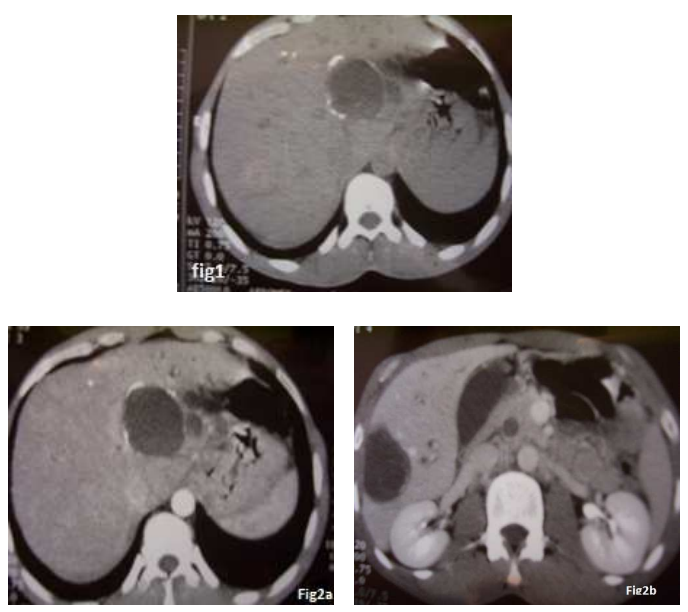

Figure 1. 2a. 2b. Axial CT scans without (Figl) and with injection of contrast material (Fig: 2a,b) showing cystic formations including one in segment IV containing peripheral calcifications and fistulized in the intrahepatic bile ducts which are dilated. 
Laboratory tests showed inflammatory syndrome (erythrocyte sedimentation rate (ESR) to $18 \mathrm{~mm}$ in the first hour) and a positive hydatid serology.

The patient underwent surgery (unroofing of the hydatid cyst, sealing of the fistula and drainage).

Postoperative period was unremarkable with no complications.

\subsection{Case 2}

A 28 years old woman with no history, with notion of contact with dogs, complained since 2 months of straight basithoracic pain when breathing. Ten days before her admission to the hospital, the patient presented dry cough, fatigue and fever. Clinical examination revealed right basithoracic dullness with absence of breath sounds and reduced tactile fremitus.

The patient had first undergone a chest X-ray (Fig 3), which showed a right moderate-sized pleural effusion.

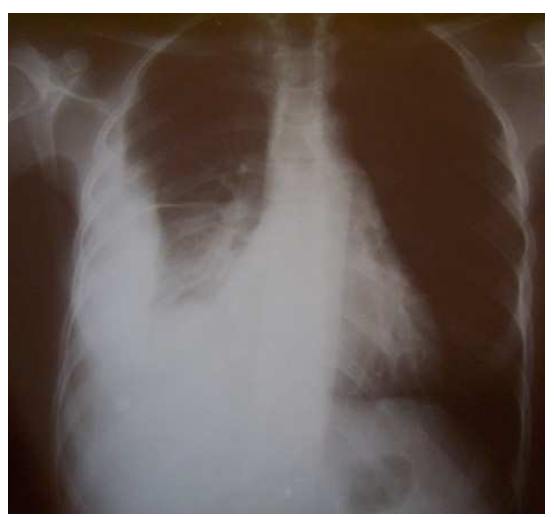

Fig 3. chest radiograph showing a right pleural effusion of moderate abundance without intra parenchymal infection.

A thoraco-abdominal CT scan was performed showing the presence of a pleural effusion associated with right scissurite, the effusion communicates through a fistula with a rounded hypodense well limited hepatic lesion, its dome contained calcified material and was not enhanced after contrast material injection (figure 4, 5). Ultrasound complement confirmed the presence of liver dome lesion with the same semiology as mentioned above.

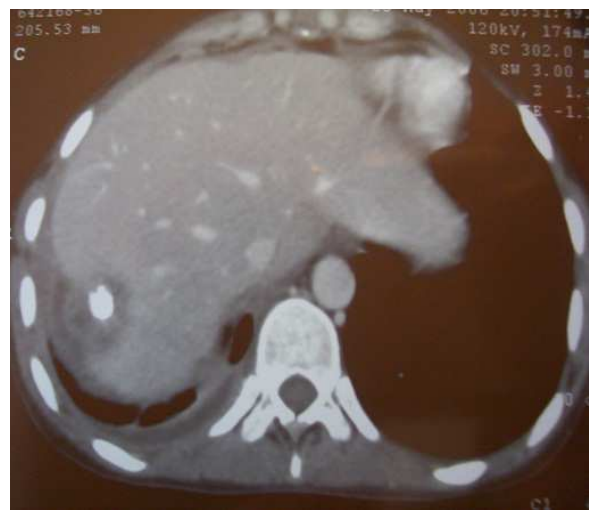

Fig 4. CT axial section after injection of contrast material showing pleural effusion communicating through a fistula with the hepatic lesion.

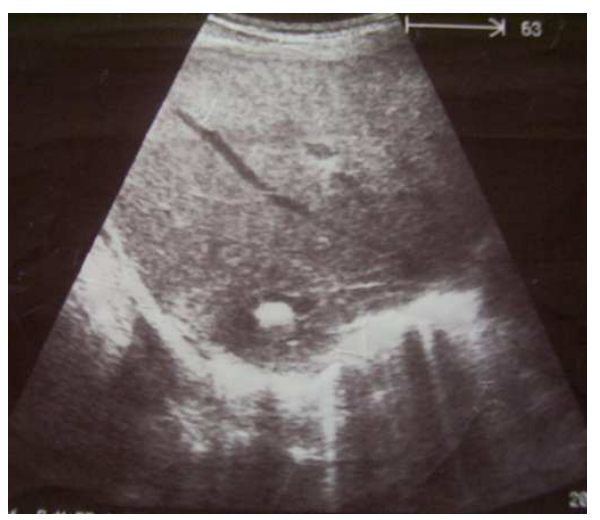

Fig 5. Ultrasound section showing the lesion of the dome of the liver containing a large calcification within it

Biology showed a discrete raised erythrocytes sedimentation rate (ESR) of $15 \mathrm{~mm}$ the first hour with a positive hydatid serology.

The patient underwent surgery with pleural fluid drainage and sealing of the fistula. Postoperative period was without complications.

\section{Discussion}

Hydatid cyst is a parasitic disease caused by the development of the larval Echinococcus granulosis form. The usual host is the dog, man being the intermediate host. All locations are possible.

Hydatid cyst rupture into the biliary tree is the most common complication (1). These fistulas are found in 30\% according to Moumen (2), 25\% according to Abi (3) and Daali (1) and 31\% according to Medarhri (4). It seems common at the right liver cysts $(5,6)$, as was the case of our first patient.

The fistula in the thorax is much uncommon and varies from 2 to $5 \%(7,8)$ as for our 2 nd case. Infection of the cystic contents, promoted by its fissuring in the biliary tree varies from 5 to $55 \%(9,10)$.

Clinical symptoms are suggestive when the patient suffers obstructive jaundice (as for the first patient) or cholangitis which is a sign of severity $(11,12)$. But the latent forms are the most common according to daali (1) and bouzidi (5). The systematic preoperative search for biliary fistula is mandatory.

Our second patient's symptoms were primarily respiratory; simulating pulmonary tuberculosis and the diagnosis of hydatid cyst was discovered fortuitously on ultrasound and was confirmed by hydatid serology.

The radiological aspects of Hydatid cyst depend on the evolution of the disease. From the young lesion, with cystic aspect; the alterations are related to the activity of the germinal membrane, to the thickening and calcification of the adventitia. Finally the reduction of hypertension produces intra cavitary membrane peeling and loss of regular limits.

The duration of each of these events is variable and there is no strict timeline. Also the classifications reflect 
imperfectly the evolution of the disease.

The most widely used due to Gharbi (13) discerns five types:

- Type 1: pure liquid image;

- Type 2: total or partial separation membranes;

- Type 3: intracavitary native hydatid cysts;

- Type 4: solid like mass;

- Type 5: calcified walls of a solid mass.

The cross-sectional imaging is the best way to recognize or diagnose these complications.

Ultrasound examination is often sufficient for simple uncomplicated hydatid cysts. It can establish the diagnosis before stage 2 or 3 , and strongly suggests it in stage 1 or 5 when epidemiological arguments are present. Serology then confirms the diagnosis.

Computed tomography scan (CT) is used secondarily. Thanks to its higher spatial resolution, it overcomes the poor conditions of examination that usually suffers ultrasound and it is very useful to show the relationship between the cyst and the vascular and biliary pedicle (5). A kysto biliary communication can be recognized when there is a biliary expansion near a cystic lesion that is not under tension. Membrane debris can be seen in the common bile duct or in the pleural effusion associated to a communicating sluice. The magnetic resonance imaging (MRI) is currently the best method in the exploration of the bile ducts $(14,15)$, especially in case of doubt remaining after CT scan, especially for lesions of stage 4 (16).

Until now, surgical treatment is the only effective way. After sterilization of the parasite, the intervention is designed to eliminate or reduce the residual cavity and treat the pleural or biliary complication.

The most adopted protocol is unroofing $(17,18,19)$, which remains a simple gesture, but the treatment of biliary fistula depends mainly on its size. If the fistula is small, closure and drainage are associated with a simple treatment, recommended in the first patient, but this method has a great weak point which is the lack of tightness with risk of prolonged bile leak and sub phrenic abscess resulting to a long hospitalization. If the fistula has a large caliber, the kysto biliary disconnection is the method of choice (20), but often requires a long hospital stay.

\section{Conclusion}

The diagnosis of the hydatid cyst is still done at the stage of complications, despite the current availability of cross-sectional imaging (ultrasound, CT and MRI).

The treatment is surgical and should be initiated before the stage of complication to make it conservative with less morbidity and mortality.

\section{Competing of Interest}

The authors don't have any competing interest.

\section{References}

[1] Daali M, Fakir Y, Hssaida R, Ameur M, Abbar M. Les kystes hydatiques du foie rompus dans les voies biliaires-à propos de 64 cas. Ann Chir. 2001;126:242-245.

[2] MOUMEN. MO., EL ALAOUI M., EL MOKHTARI M., EL FARES F. Les kystes hydatiques du foie. A propos de 670 cas dont 552 compliqués. Sem Hôp Paris 69 : 7225,1993.

[3] Abi F., El Fares F., Bouzidi A. Les kystes hydatiques du foie. A propos de 181 cas compliqués. Lyon Chir 1988 ; 40 : $418-420$

[4] Medarhri J, EL Ounani M, Echarrab M, Louchi A, Alami F, Amraoui M, Errogani A, Chkof R, Balafrej S. Les kystes hydatiques du foie rompus dans les voies biliaires à propos de 88 cas expérience des urgences chirurgicales viscérales Rabat. Médecine du Maghreb. 2001;86:45-48

[5] Bouzidi A, Chehab F. Traitement chirurgical des fistules biliokystiques d'origine hydatique : 83 cas. J Chir 1997 ; 134 114-8.

[6] Serguney S, Tortum O, Haydar A. Les kystes hydatiques compliqués du foie. Ann Chir 1991 ; 45 : 584-9.

[7] MOUMEN M., EL FARES F. Les fistules bilio-bronchiques d'origine hydatique. A propos de 8 cas. J. Chir. 1991,128, $\mathrm{n}^{\circ} 4,188-192$.

[8] MZABI R., BACH HANBA K. Traitement des kystes hydatiques du foie ouverts dans les bronches. A propos de 24 cas. Mem. Acad Chir. 1978,104,404,412

[9] CHIGOT J. P., LANGLOIS P., TEBOUL F., GLOT J. P., GENTILINI M., MERCADIER M. Le traitement des kystes hydatiques du foie. Ann. Chir 1986, 40, 177-182.

[10] MOUMEN M., EL ALAOUI M.E., MEHHANE M., JAMIL D., MOKHTARI M., EL FARES F. La résection du dôme saillant du kyste hydatique du foie. A propos de 360 cas. J Chir (Paris). 1990 Feb;127(2):83-6.

[11] Kourias B. Échinococcose péritonéale secondaire. Marseille chirurgical $1966 ; 18: 389-99$.

[12] Ennabli E, Mouche A, Hachaichi A. Les kystes hydatiques du foie ouverts dans les voies biliaires. Sem Hôp 1986 ; 62 : 2173-80.

[13] Gharbi HA, Hassine W, Brauner MW, Dupuch K. Ultrasound examination of the hydatic liver. Radiology. 1981 May;139(2):459-463.

[14] Ernst O, Asselah T, Fakir Y. Cholangio-wirsungographie par IRM. Ann Chir 1997 ; 51 : 1111-4.

[15] Cervi C, Aube C, Tuech JJ, Pessaux P, Regenet N, Burtin P, Arnaud JP. La cholangiographie par résonance magnétique nucléaire en pathologie biliaire. Etude prospective chez 60 patients. Ann Chir $2000 ; 125$ : 428-34.

[16] Les kystes hydatiques du foie rompus dans les voies biliaires: à propos de 120 cas Mountassir Moujahid1,\&, Mohamed Tarik Tajdine1. Pan Afr Med J. 2011;10:43.

[17] Balafrej S, El Alami E, El Madhi T, et al. La rupture du kyste hydatique dans les voies biliaires. Résultats du traitement chirurgical et place de la cholédocostomie transhépatico kystique. Lyon Chir 1995 ; 40 : 177-82. 
[18] Chehab F, Khail D, Bouzidi A. La surveillance postopératoire du kyste hydatique du foie opéré. Med Maghreb 1997 ; 86 : 41-2.

[19] Maaouni A. Chirurgie du kyste hydatique du foie. Chirurgie $1989 ; 115: 61-9$.
[20] Settaf A, Bargach S, Lamlou M, Oudghiri M. Traitement de la fistule kystobiliaire du kyste hydatique du foie. J Chir $1991 ; 128: 133-8$ 